\title{
Elevated highly sensitive C-reactive protein and D-dimer levels are associated with food insecurity among people living with HIV in Pune, India
}

\author{
Sandesh Patil ${ }^{1, *}$, Dileep Kadam ${ }^{2}$, Nicky Mehtani ${ }^{3}$, Shashikala Sangle ${ }^{2}$, \\ Ivan Marbaniang ${ }^{1, *}$, Vandana Kulkarni ${ }^{1}$, Dhananjay Shere ${ }^{1}$, Prasad Deshpande ${ }^{1}$, \\ Gauri Dhumal $^{1}$, Nishi Suryavanshi ${ }^{1}$, Nikhil Gupte ${ }^{1,3}$, Robert Bollinger ${ }^{3}$, Andrea Deluca ${ }^{3}$, \\ Neetal Nevrekar ${ }^{1}$, Pramila Menon ${ }^{4}$, Rama Kawade ${ }^{4}$, Mansi Patil ${ }^{4}$, Amita Gupta ${ }^{3}$ and \\ Vidya Mave ${ }^{1,3}$ \\ 'Byramjee Jeejeebhoy Government Medical College - Johns Hopkins University Clinical Research Site, 1st Floor, \\ Pathology Museum, J P Narayan Road, Pune 411 001, India: ${ }^{2}$ Byramjee Jeejeebhoy Government Medical College \\ and Sassoon General Hospitals, Pune, India: ${ }^{3}$ Johns Hopkins School of Medicine, Baltimore, MD, USA: ${ }^{4}$ Department \\ of Genetics, Immunology, Biotechnology and Nutrition, Maharashtra University of Health Sciences, Regional Centre, \\ Pune, India
}

Submitted 26 June 2018: Final revision received 21 December 2018: Accepted 9 January 2019: First published online 4 March 2019

\begin{abstract}
Objective: To assess the prevalence and determinants of food insecurity among people living with HIV (PLWH) in Pune, India and its association with biomarkers known to confer increased risks of morbidity and mortality in this population. Design: Cross-sectional analysis assessing food insecurity using the standardized Household Food Insecurity Access Scale. Participants were dichotomized into two groups: food insecure and food secure. Logistic regression models were used to assess associations between socio-economic, demographic, clinical, biochemical factors and food insecurity.

Setting: Antiretroviral therapy (ART) centre of Byramjee Jeejeebhoy Government Medical College and Sassoon General Hospitals (BJGMC-SGH), Pune, a large publicly funded tertiary and teaching hospital in western India.

Particpants: Adult ( $\geq 18$ years) PLWH attending the ART centre between September 2015 and May 2016 who had received ART for either $\leq 7 \mathrm{~d}$ (ART-naïve) or $\geq 1$ year (ART-experienced).

Results: Food insecurity was reported by $40 \%$ of 483 participants. Independent risk factors (adjusted OR; 95\% CI) included monthly family income < INR 5000 $(\sim 70$ USD; $13 \cdot 2$; CI $5 \cdot 4,32 \cdot 2)$ and consuming $\geq 4$ non-vegetarian meals per week $(4.7 ; 1.9,11.9)$. High-sensitivity C-reactive protein (hs-CRP) $\geq 0.33 \mathrm{mg} / \mathrm{dl}(1 \cdot 6 ; 1.04$, $2 \cdot 6)$ and D-dimer levels $0 \cdot 19-0.31 \mu \mathrm{g} / \mathrm{ml}(1 \cdot 6 ; 1 \cdot 01,2 \cdot 6)$ and $\geq 0.32 \mu \mathrm{g} / \mathrm{ml}(1 \cdot 9 ; 1 \cdot 2$, 3.2) were also associated with food insecurity.

Conclusions: More than a third of the study participants were food insecure. Furthermore, higher hs-CRP and D-dimer levels were associated with food insecurity. Prospective studies are required to understand the relationship between food insecurity, hs-CRP and D-dimer better.
\end{abstract}

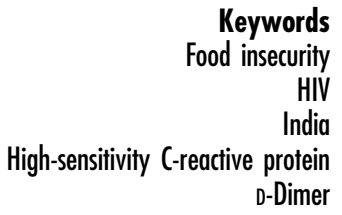

Over the past two decades, the Government of India has dramatically expanded access to antiretroviral therapy (ART) among people living with HIV $(\mathrm{PLWH})^{(1)}$; however, the utility of these medications is hindered by a concurrent pandemic of food insecurity that abounds in this population $^{(2)}$. The lack of ability to obtain nutritionally adequate food can directly accelerate the progression to AIDS through the exacerbation of poor immunological status ${ }^{(3,4)}$ and indirectly perpetuate the development of poor quality of life ${ }^{(5)}$. In parallel, due to its disproportionate incidence among working-age adults, HIV itself can increase the risk of food insecurity, as it often detracts from an individual's ability to feed and care for family members ${ }^{(6,7)}$.

In light of widespread evidence demonstrating the relationship between food insecurity and poor HIV outcomes $^{(7-9)}$, the World Health Assembly issued a May 2006 
resolution urging countries to identify 'nutrition interventions for immediate integration into HIV/AIDS programming,(10) - a policy position backed by the Joint United Nations Programme on HIV and AIDS (UNAIDS), the World Food Programme and the $\mathrm{WHO}^{(2)}$. However, over a decade later, despite the formulation of extensive nutritional guidelines for PLWH ${ }^{(11)}$ concurrent with efforts to universalize ART access, the National AIDS Control Organisation (NACO) - India's premier governmental HIV agency - has yet to implement a food or nutrition programme. Notably, there have been robust political efforts aimed at reducing food insecurity in the general population. Initiatives like the 'mid-day meal' at government schools $^{(12)}$, the anganwadi system for pregnant and lactating mothers, and the National Food Security Act of $2013^{(12,13)}$ have propagated a paradigm shift in India's consideration of food insecurity from a welfare- to rightsbased approach ${ }^{(12)}$. These and other global efforts have helped reduce the prevalence of undernourishment in India from $20 \%$ in $2004-2006$ to $14 \%$ in $2014-2016^{(14,15)}$; however, the impact of these national programmes on PLWH, who face a unique set of barriers to achieving food security $^{(6,16)}$, is unclear.

One factor that has likely hindered the development of a food programme under NACO is a lack of substantial evidence demonstrating the relationship between food insecurity and HIV in the Indian population. To date, we found only two published studies - conducted in West Bengal (eastern India) ${ }^{(17)}$ and Karnataka (southern India) ${ }^{(5)}$ - that specifically examine the prevalence of food insecurity among PLWH in India and their results reveal marked variability, with prevalence ranging from 19 to $49 \%$. India's heterogeneous population makes it difficult to extrapolate such findings to other geographic regions. Moreover, no studies of which we are aware have investigated the effects of biomarkers of HIV disease progression on food security.

Accordingly, the current study sought to define the prevalence of food insecurity among PLWH in Pune, Maharashtra - a district known to have an HIV prevalence of $0.67 \%{ }^{(18)}$, nearly three times the national prevalence of $0.26 \%{ }^{(19)}$. Secondary objectives included identifying predictors of food insecurity and elucidating the relationship between food insecurity and biomarkers known to confer increased risks of morbidity and mortality in this population.

\section{Methods}

\section{Study population}

The ART treatment centre at Byramjee Jeejeebhoy Government Medical College and Sassoon General Hospitals (BJGMC-SGH) is a governmentally operated outpatient clinic that provides free medication to PLWH in Pune and surrounding districts of Maharashtra. A cross-sectional study on food insecurity was performed among conveniently sampled adult PLWH ( $\geq 18$ years) attending the ART centre between 1 September 2015 and 24 May 2016. Adults PLWH who had received ART for $\leq 7 \mathrm{~d}$ (ART-naïve) or $\geq 1$ year (ART-experienced) were eligible for enrolment. This eligibility criterion was formulated to facilitate comparison by treatment status.

\section{Data collection and procedures}

The Household Food Insecurity Access Scale (HFIAS) is a nine-question standardized survey instrument originally designed by the US Department of Agriculture for the measurement of household access to food ${ }^{(20)}$. The questionnaire, which has been validated in several countries including India ${ }^{(21)}$, was administered by trained counsellors to consenting participants through in-person interviews in the locally spoken languages of Marathi or Hindi. In addition to the HFIAS, sociodemographic information including age, sex, self-reported monthly family income, years of education, dietary habits and duration of ART treatment were recorded at the time of enrolment. Dietary habits were categorized as 'strict vegetarian' (individuals who never consume meat, poultry and seafood), 'mostly vegetarian' (individuals who eat meat, poultry or seafood in fewer than four meals per week) and 'mostly nonvegetarian' (individuals who eat meals involving meat, poultry or seafood four or more times per week). Weight was measured using a standardized weighing scale and height by a stadiometer. After initial data collection, study participants were characterized as food secure, mildly food insecure, moderately food insecure or severely food insecure per HFIAS scores (algorithm provided in the online supplementary material, Supplemental Table 1). All data were captured electronically, stored on a cloud-based server and maintained by Persistent Systems Inc.

\section{Laboratory measurements}

CD 4 cell counts were abstracted from participants' health records. Investigations not routinely done under the national programme were performed locally at our Division of AIDS (DAIDS)-approved laboratory. Among these, HIV-RNA levels were measured using the Abbott m2000 Real Time PCR. Total cholesterol, HDL-cholesterol, LDL-cholesterol, TAG, D-dimer and high-sensitivity C-reactive protein (hs-CRP) were measured using the Roche cobas c 111 analyser. The Bio-Plex Pro ${ }^{\mathrm{TM}}$ 4-plex cytokine panel was used to quantify TNF $\alpha$, monocyte chemoattractant protein-1, IL-6 and IL-10.

\section{Statistical analyses}

Participants categorized as food secure and food insecure (mild, moderate or severe food insecurity) were compared on the bases of age, sex, family income, education, location of residence, dietary habits, BMI, ART duration and 
the levels of biomarkers. Biomarkers that showed increased skewness in either direction were logtransformed or otherwise categorized by tertiles. Univariate logistic regression was employed to identify risk factors and biomarkers associated with food insecurity. Multivariable logistic regression models were constructed using covariates that showed statistical significance in univariate models or that were identified a priori. Statistical significance was determined using an $\alpha$ set at 0.05 and analyses were conducted using the statistical software package Stata version 14 .

\section{Results}

A total of 483 participants were included in the current analysis, 40 (95\% CI 36, 45)\% ( $n$ 194) of whom were characterized as food insecure per evaluation by HFIAS, including $12 \%$ ( $n$ 58) with mild, $22 \%$ ( $n$ 109) with moderate and $6 \%(n$ 27) with severe food insecurity. Fortyseven per cent of participants ( $n$ 225) were male, $20 \%$ ( $n$ 95) reported a family income of less than INR 5000 ( 70 USD), $25 \%$ ( $n$ 122) had less than 5 years of education and 9\% ( $n$ 42) were strictly vegetarian (Table 1$)$.

Within the study population, $29 \%$ participants ( $n$ 141) were also found to be underweight $\left(\mathrm{BMI}<18.5 \mathrm{~kg} / \mathrm{m}^{2}\right)$; however, among participants characterized as food insecure, only $28 \%(n 53)$ were underweight $(P=0 \cdot 68)$. The median CD 4 cell count among participants was 389 (interquartile range 246-609) cells $/ \mathrm{mm}^{3}$, and $51 \%$ ( $n$ 248) had undetectable HIV viral loads. Twenty-one per cent ( $n$ 100) were ART-naïve and 58\% ( $n$ 278) had dyslipidaemia (Table 2).

In univariate models, monthly family income of $<$ INR $5000(\mathrm{OR}=26 \cdot 3 ; 95 \% \mathrm{CI} 11 \cdot 7,59 \cdot 3)$, having received $<5$ years of education $(\mathrm{OR}=2.9 ; 95 \% \mathrm{CI} 1 \cdot 8,4.8)$ and consuming $\geq 4$ non-vegetarian meals per week $(\mathrm{OR}=6 \cdot 9 ; 95 \%$ CI $3 \cdot 1,15 \cdot 8)$ had positive associations with the odds of being food insecure. Living in urban non-slum areas, on the other hand, showed a negative association with food insecurity (OR=0.5; 95\% CI 0.3, 0.7; Table 2).

A multivariable model adjusted for participant age, sex, family income, education level, living location and dietary habits demonstrated increased odds of food insecurity among participants whose diet consisted of $\geq 4$ nonvegetarian meals per week compared with their strictly vegetarian counterparts (adjusted OR $(\mathrm{aOR})=4 \cdot 7 ; 95 \% \mathrm{CI}$ 1.9, 11.9). Similarly, a positive association was found between food insecurity and family income, which was more pronounced among participants earning < INR 5000 per month $(\mathrm{aOR}=13 \cdot 2 ; 95 \% \mathrm{CI} 5 \cdot 4,32 \cdot 2)$. There was no significant difference in the odds of food insecurity among participants on the bases of sex, years of education or living locality (Table 1).

In separate univariate models assessing the association between food insecurity and biomarkers, the highest tertiles of hs-CRP (OR $=1.6 ; 95 \%$ CI 1.03, 2.5) and D-dimer (OR $=1.9 ; 95 \%$ CI $1.2,2.9)$ were found to be significant. Multivariable models with adjustments for participant age, sex, CD4 count, HIV-RNA detectability and ART duration demonstrated significant odds of food insecurity among participants with elevated hs-CRP (aOR $=1 \cdot 6$; $95 \%$ CI 1.04, 2.6) and D-dimer levels. The association between food insecurity and D-dimer levels was strongest among participants with levels $\geq 0.32 \mu \mathrm{g} / \mathrm{ml}(\mathrm{aOR}=1.9$; $95 \%$ CI 1.2 , $3 \cdot 2)$ but was also significant for those with levels between 0.19 and $0.31 \mu \mathrm{g} / \mathrm{ml}(\mathrm{aOR}=1 \cdot 6 ; 95 \%$ CI 1.01, 2.6) compared with those having levels $<0 \cdot 19 \mu \mathrm{g} / \mathrm{ml}$ (see Fig. 1 and online supplementary material, Supplemental Table 2). No significant associations were found between food insecurity and other inflammatory biomarkers (IL-6, IL-10, TNF $\alpha$, monocyte chemoattractant protein-1), including CD4 count and viral load detectability, or BMI (Table 2).

\section{Discussion}

\section{Food insecurity prevalence}

The prevalence of food insecurity among PLWH in the present study was $40 \%$, corroborating findings from other studies reporting increased barriers to food security among $\mathrm{PLWH}^{(4-7)}$ and suggesting the need for interventions that target food security within the current scope of the Indian national HIV response programme.

Overall, the food insecurity prevalence in our study population was lower than the $49 \%$ found among PLWH receiving care at an ART centre in eastern India ${ }^{(17)}$ and significantly higher than the $14-16 \%$ reported from southern India $^{(5)}$. These variations are likely due to differing characteristics among PLWH in the three distinct geographical regions of India. For example, while substantial proportions of the participants in our study and the eastern India study reported fewer than 5 years of education (25 and $32.3 \%$, respectively), a relatively small percentage of participants in the southern India study reported less than 4 years of education (7.2\%). Although difficult to compare across different geographic settings, income variation among the populations may have also contributed to the divergent food insecurity prevalence estimates $^{(5,17)}$. Interestingly, in a cross-sectional study that evaluated food security among PLWH in Aurangabad, Maharashtra - located just $250 \mathrm{~km}$ west of Pune - 99\% were characterized as food insecure ${ }^{(22)}$. However, despite the geographic similarities with Pune, it remains difficult to directly compare the study populations, as the Aurangabad study had been conducted during the peak of a global food crisis in 2008.

\section{Sociodemographic predictors of food insecurity}

While prior studies in India ${ }^{(5,17)}$ and elsewhere ${ }^{(23-25)}$ have demonstrated male PLWH to have greater levels of food 


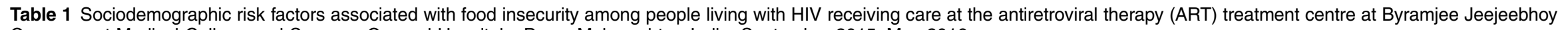
Government Medical College and Sassoon General Hospitals, Pune, Maharashtra, India, September 2015-May 2016

\begin{tabular}{|c|c|c|c|c|c|c|c|c|c|c|}
\hline & \multicolumn{2}{|c|}{$\begin{array}{c}\text { Total } \\
(n \text { 483) }\end{array}$} & \multicolumn{2}{|c|}{$\begin{array}{l}\text { Food insecure } \\
\qquad(n 194)\end{array}$} & \multicolumn{2}{|c|}{$\begin{array}{l}\text { Food secure } \\
\text { (n 289) }\end{array}$} & \multirow[b]{2}{*}{ OR } & \multirow[b]{2}{*}{$95 \% \mathrm{Cl}$} & \multirow[b]{2}{*}{$\mathrm{aOR}^{*}$} & \multirow[b]{2}{*}{$95 \% \mathrm{Cl}$} \\
\hline & $n$ or median & $\%$ or IQR & $n$ or median & $\%$ or IQR & $n$ or median & $\%$ or IQR & & & & \\
\hline \multicolumn{11}{|l|}{ Age decile (years) } \\
\hline Median and IQR & 40 & $35-46$ & 40 & $35-45$ & 40 & $35-46$ & - & - & - & - \\
\hline$<25$ & 27 & 6 & 7 & 4 & 20 & 7 & 1.0 & Ref. & 1.0 & Ref. \\
\hline $25-34.9$ & 101 & 21 & 44 & 23 & 57 & 20 & $2 \cdot 2$ & $0.8,5 \cdot 7$ & 3.3 & $1.03,10.6$ \\
\hline $35-44.9$ & 224 & 46 & 96 & 49 & 128 & 44 & $2 \cdot 1$ & $0.9,5.3$ & $2 \cdot 8$ & $0.9,8.6$ \\
\hline$\geq 45$ & 131 & 27 & 47 & 24 & 84 & 29 & $1 \cdot 6$ & $0 \cdot 6,4 \cdot 1$ & $2 \cdot 0$ & $0.6,6.5$ \\
\hline \multicolumn{11}{|l|}{ Sex } \\
\hline Male & 225 & 47 & 84 & 43 & 141 & 49 & 1.0 & Ref. & 1.0 & Ref. \\
\hline Female & 258 & 53 & 110 & 57 & 148 & 51 & 1.2 & $0.9,1.8$ & 0.9 & $0.6,1.6$ \\
\hline \multicolumn{11}{|l|}{ Family income (INR) } \\
\hline$\geq 15000$ & 108 & 22 & 9 & 5 & 99 & 34 & 1.0 & Ref. & 1.0 & Ref. \\
\hline$<5000$ & 95 & 20 & 67 & 34 & 28 & 10 & $26 \cdot 3$ & $11 \cdot 7,59 \cdot 3$ & $13 \cdot 2$ & $5.4,32.2$ \\
\hline 5000-9999 & 175 & 36 & 96 & 49 & 79 & 27 & 13.4 & $6 \cdot 3,28 \cdot 1$ & 10.4 & $4 \cdot 7,23.0$ \\
\hline $10000-14999$ & 105 & 22 & 22 & 11 & 83 & 29 & 2.9 & $1 \cdot 3,6 \cdot 7$ & $2 \cdot 3$ & $0.9,5.5$ \\
\hline \multicolumn{11}{|l|}{ Years of education } \\
\hline$>9$ & 183 & 38 & 52 & 27 & 131 & 45 & 1.0 & Ref. & 1.0 & Ref. \\
\hline$<5$ & 122 & 25 & 66 & 34 & 56 & 19 & 2.9 & $1.8,4.8$ & 1.6 & $0.9,3.0$ \\
\hline $5-9$ & 178 & 37 & 76 & 39 & 102 & 35 & 1.9 & $1.2,2.9$ & 1.4 & $0.8,2.4$ \\
\hline \multicolumn{11}{|l|}{ Living location } \\
\hline Urban (slum) & 114 & 24 & 59 & 30 & 55 & 19 & 1.0 & Ref. & 1.0 & Ref. \\
\hline Rural & 80 & 17 & 43 & 22 & 37 & 13 & $1 \cdot 1$ & $0.6,1.9$ & 0.9 & $0.4,1.9$ \\
\hline Peri-urban & 22 & 5 & 4 & 2 & 18 & 6 & 0.2 & $0.07,0.6$ & 0.3 & $0.07,1.0$ \\
\hline Urban (non-slum) & 267 & 55 & 88 & 45 & 179 & 62 & 0.5 & $0.3,0.7$ & 0.6 & $0.3,1.0$ \\
\hline \multicolumn{11}{|l|}{ Non-vegetarian food $†$} \\
\hline Strict vegetarian & 42 & 9 & 8 & 4 & 34 & 12 & 1.0 & Ref. & 1.0 & Ref. \\
\hline$<4$ meals/week & 217 & 45 & 48 & 25 & 169 & 58 & 1.2 & $0.5,2.8$ & $1 \cdot 1$ & $0.4,2.7$ \\
\hline$\geq 4$ meals/week & 217 & 45 & 135 & 70 & 82 & 28 & 6.9 & $3 \cdot 1,15 \cdot 8$ & 4.7 & $1.9,11.9$ \\
\hline Missing & 7 & 1 & 3 & 1 & 4 & 1 & - & - & - & - \\
\hline
\end{tabular}

IQR, interquartile range; ref., reference category.

and \% unless indicated otherwise. Significant results are indicated in bold.

*Multivariable logistic regression was used with adjustments made for patient age, sex, family income, years of education, living location and meat consumption.

†Non-vegetarian food includes meat, poultry or seafood. 
Table 2 Biochemical markers associated with food insecurity among people living with HIV receiving care at the antiretroviral therapy (ART) treatment centre at Byramjee Jeejeebhoy Government Medical College and Sassoon General Hospitals, Pune, Maharashtra, India, September 2015-May 2016

\begin{tabular}{|c|c|c|c|c|c|c|c|c|c|c|}
\hline & \multicolumn{2}{|c|}{$\begin{array}{c}\text { Total } \\
(n \text { 483) }\end{array}$} & \multicolumn{2}{|c|}{$\begin{array}{l}\text { Food insecure } \\
\quad(n \text { 194) }\end{array}$} & \multicolumn{2}{|c|}{$\begin{array}{l}\text { Food secure } \\
\quad(n \text { 289) }\end{array}$} & \multirow[b]{2}{*}{ OR } & \multirow[b]{2}{*}{$95 \% \mathrm{Cl}$} & \multirow[b]{2}{*}{$\mathrm{aOR}$} & \multirow[b]{2}{*}{$95 \% \mathrm{Cl}$} \\
\hline & $n$ or median & $\%$ or IQR & $n$ or median & $\%$ or IQR & $n$ or median & $\%$ or IQR & & & & \\
\hline \multicolumn{11}{|l|}{$\mathrm{BMI}\left(\mathrm{kg} / \mathrm{m}^{2}\right)$} \\
\hline$<18.5$ (underweight) & 141 & 29 & 53 & 28 & 88 & 30 & $1 \cdot 0$ & Ref. & - & - \\
\hline $18.5-24.9$ (normal) & 255 & 53 & 102 & 53 & 153 & 53 & $1 \cdot 1$ & $0.7,1.7$ & - & - \\
\hline$\geq 25.0$ (overweight \& obese) & 78 & 16 & 34 & 18 & 44 & 15 & 1.3 & $0.7,2 \cdot 3$ & - & _ \\
\hline Missing & 9 & 2 & 5 & 3 & 4 & 1 & - & - & - & - \\
\hline \multicolumn{11}{|l|}{ CD4 cell count (cells $/ \mathrm{mm}^{3}$ ) } \\
\hline Median and IQR & 389 & $246-609$ & 367 & $233-583$ & 402 & $254-616$ & - & - & - & - \\
\hline$>500$ & 174 & 36 & 61 & 31 & 113 & 39 & 1.0 & Ref. & - & - \\
\hline$<350$ & 210 & 43 & 90 & 46 & 120 & 42 & 1.4 & $0.9,2 \cdot 1$ & - & - \\
\hline $350-500$ & 94 & 19 & 42 & 22 & 52 & 18 & 1.5 & $0.9,2.5$ & - & - \\
\hline Missing & 5 & 1 & 1 & 0.5 & 4 & 1 & - & - & - & - \\
\hline \multicolumn{11}{|l|}{ Viral load } \\
\hline Undetectable ( $<40$ copies) & 248 & 51 & 98 & 51 & 150 & 52 & 1.0 & Ref. & - & - \\
\hline Detectable ( $\geq 40$ copies) & 235 & 49 & 96 & 49 & 139 & 48 & $1 \cdot 1$ & $0.7,1.5$ & - & - \\
\hline \multicolumn{11}{|l|}{ Time on ART } \\
\hline$\leq 7 \mathrm{~d}$ (naïve) & 100 & 21 & 40 & 21 & 60 & 21 & 1.0 & Ref. & - & - \\
\hline$\geq 1-5$ years & 154 & 32 & 68 & 35 & 86 & 30 & $1 \cdot 2$ & $0.7,1.9$ & - & - \\
\hline$>5-10$ years & 169 & 35 & 64 & 33 & 105 & 36 & 0.9 & $0.6,1.5$ & - & - \\
\hline$>10$ years & 60 & 12 & 22 & 11 & 38 & 13 & 0.9 & $0.4,1.7$ & - & - \\
\hline \multicolumn{11}{|l|}{ Dyslipidaemia* } \\
\hline No & 183 & 38 & 81 & 42 & 102 & 35 & 1.0 & Ref. & - & - \\
\hline Yes & 278 & 58 & 109 & 56 & 169 & 58 & 0.8 & $0.6,1.2$ & - & - \\
\hline Missing & 22 & 5 & 4 & 2 & 18 & 6 & - & - & - & - \\
\hline \multicolumn{11}{|l|}{$\mathrm{D}-$ Dimer tertile $(\mu \mathrm{g} / \mathrm{ml})$} \\
\hline$\leq 0.18$ & 171 & 35 & 54 & 28 & 117 & 40 & 1.0 & Ref. & \multirow{3}{*}{\multicolumn{2}{|c|}{$\ddagger$}} \\
\hline$\overline{0.19-0.31}$ & 153 & 32 & 66 & 34 & 87 & 30 & 1.6 & $1.04,2.6$ & & \\
\hline \multicolumn{9}{|l|}{ hs-CRP tertile (mg/dl) } & & \\
\hline$\leq 0.10$ & 163 & 34 & 56 & 29 & 107 & 37 & $1 \cdot 0$ & Ref. & \multirow{3}{*}{\multicolumn{2}{|c|}{$\ddagger$}} \\
\hline $0.101-0.32$ & 159 & 33 & 64 & 33 & 95 & 33 & $1 \cdot 3$ & $0.8,2 \cdot 0$ & & \\
\hline$\geq 0.33$ & 161 & 33 & 74 & 38 & 87 & 30 & 1.6 & $1.03,2.5$ & & \\
\hline \multicolumn{11}{|l|}{$\mathrm{IL}-6 \geq 0.75(\mathrm{pg} / \mathrm{ml}) \dagger$} \\
\hline No & 176 & 36 & 64 & 33 & 112 & 39 & $1 \cdot 0$ & Ref. & - & - \\
\hline Yes & 176 & 36 & 73 & 38 & 103 & 36 & $1 \cdot 2$ & $0.8,1.9$ & - & - \\
\hline Missing & 131 & 27 & 57 & 29 & 74 & 26 & - & - & - & - \\
\hline \multicolumn{11}{|l|}{$\mathrm{IL}-10 \geq 1.08(\mathrm{pg} / \mathrm{ml}) \dagger$} \\
\hline No & 182 & 38 & 67 & 35 & 115 & 40 & 1.0 & Ref. & - & - \\
\hline Yes & 192 & 40 & 79 & 41 & 113 & 39 & $1 \cdot 2$ & $0.7,1.8$ & - & - \\
\hline Missing & 109 & 23 & 48 & 25 & 61 & 21 & - & - & - & - \\
\hline \multicolumn{11}{|l|}{ TNFa $\geq 1.12(\mathrm{pg} / \mathrm{ml}) \dagger$} \\
\hline No & 174 & 36 & 73 & 38 & 101 & 35 & 1.0 & Ref. & - & - \\
\hline Yes & 177 & 50 & 72 & 37 & 105 & 36 & 0.9 & $0.6,1.4$ & - & - \\
\hline Missing & 132 & 27 & 49 & 25 & 83 & 29 & - & - & - & - \\
\hline \multicolumn{11}{|l|}{ MCP-1 $\geq 3.88(\mathrm{pg} / \mathrm{ml}) \dagger$} \\
\hline No & 244 & 51 & 103 & 53 & 141 & 49 & $1 \cdot 0$ & Ref. & - & - \\
\hline Yes & 233 & 48 & 88 & 45 & 145 & 50 & 0.8 & $0.6,1 \cdot 2$ & - & - \\
\hline Missing & 6 & 1 & 3 & 2 & 3 & 1 & - & - & - & - \\
\hline
\end{tabular}

IQR, interquartile range; hs-CRP, high-sensitivity C-reactive protein; MCP-1, monocyte chemoattractant protein-1; ref., reference category.

Results are presented as $n$ and \% unless indicated otherwise. Significant results are indicated in bold.

*Dyslipidaemia used as an umbrella term to include people living with HIV with any of the following: total cholesterol $\geq 200 \mathrm{mg} / \mathrm{dl}$, TAG $\geq 150 \mathrm{mg} / \mathrm{dl}$, LDLcholesterol $\geq 130 \mathrm{mg} / \mathrm{dl}$ or HDL-cholesterol $<40 \mathrm{mg} / \mathrm{dl}$.

†Cut-offs derived using the median values of log-transformed distributions. Missing for BMl are participants missing either weight or height measurements; missing for dyslipidaemia are those with extremely high TAG values precluding calculation of LDL-cholesterol values; values of biomarkers that were below the level of machine calibration were treated as missing.

¥Multivariable models for the associations between food insecurity, hs-CRP and D-dimer are shown in Fig. 1 and the online supplementary material, Supplemental Table 2.

security than their female counterparts, the current study showed similar rates of food insecurity among the sexes. Studies that have shown increased food insecurity among females often explains this result by suggesting that females deprive themselves of meals during food shortages to ensure that male household members and children are able to eat; however, the HFIAS specifically frames questions to inquire upon aspects of household- rather than individual-level food security ${ }^{(20)}$. Therefore, the nearequivalent rates of reported food insecurity among the sexes in the current study may reflect a tendency of the male respondents of our study to more accurately reflect 
(a)

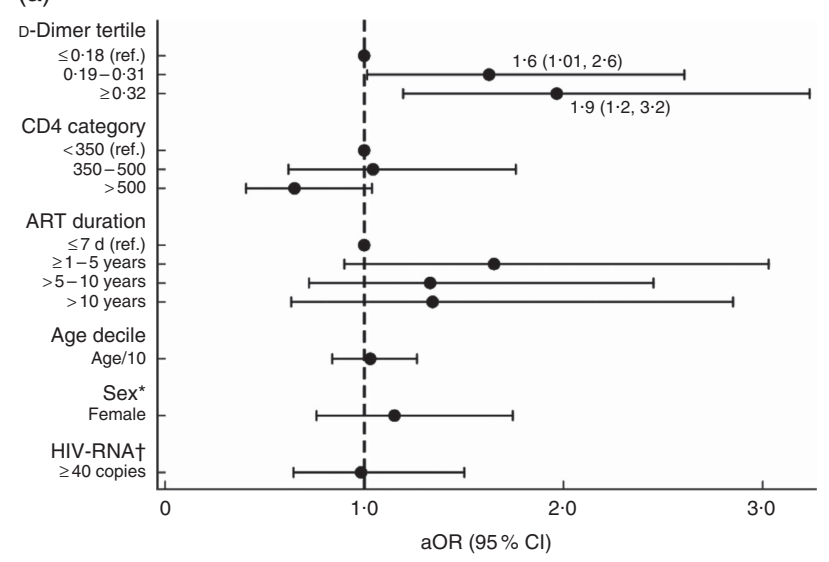

(b)

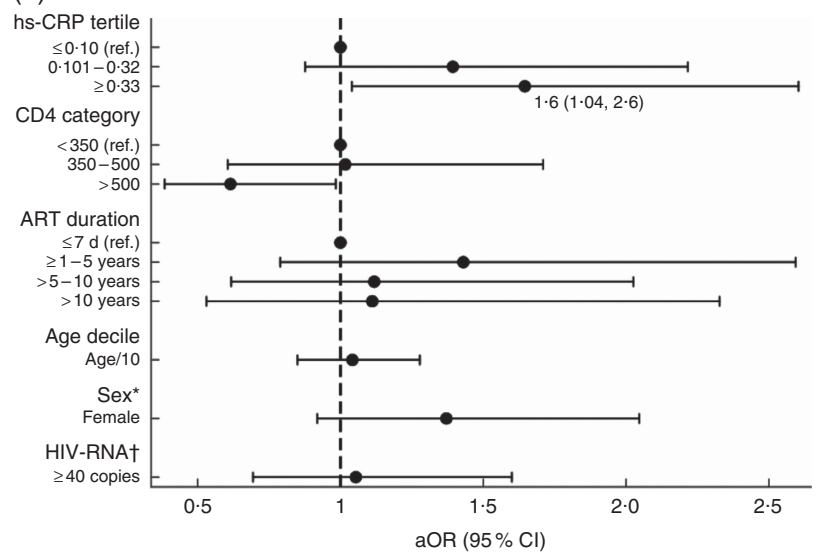

Fig. 1 Adjusted models of the association between food insecurity and (a) D-dimer and (b) high-sensitivity C-reactive protein (hs$\mathrm{CRP}$ ) in people living with HIV recruited from the antiretroviral therapy (ART) treatment centre at Byramjee Jeejeebhoy Government Medical College and Sassoon General Hospitals, Pune, Maharashtra, India, September 2015-May 2016. Results are presented as adjusted OR (aOR; 0 ) with their $95 \% \mathrm{Cl}$ represented by horizontal lines; both regression models are adjusted for CD4, ART duration, age, sex and HIV-RNA (ref., reference category). *Sex: ref. is male. †HIV-RNA: ref. is <40 copies. Numerical values of the point estimates along with their $95 \% \mathrm{Cl}$ are given in the online supplementary material, Supplemental Table 2

upon and demonstrate awareness of issues faced by other family members.

Our analysis also demonstrated a higher prevalence of food insecurity among PLWH accustomed to eating four or more non-vegetarian meals per week. This is likely due to the higher costs and resources needed with obtaining and cooking non-vegetarian foods.

Lower family income among PLWH was also shown to have a positive association with food insecurity, a finding that has also been established in other populations ${ }^{(5,17,23-25)}$. While this underscores the importance of controlling for income as a marker of socio-economic status, it is clear that income is not the sole predictor of food insecurity, as the majority of PLWH characterized as food insecure in the present study were not in the lowest income category.

\section{Associations of biomarkers with food insecurity}

The present study is novel in examining the relationship between food insecurity and biochemical predictors that have previously been shown to have increased long-term risks of morbidity and mortality in PLWH. Some observational studies on hs-CRP have reported it to be an independent predictor of CVD risk in PLWH, even in the absence of traditional CVD risk factors ${ }^{(26,27)}$. Similarly, associations of elevated D-dimer levels with increased risks of all-cause mortality and serious non-AIDS conditions have been described ${ }^{(28)}$. We observed a positive association between food insecurity and elevated levels of both these biochemical markers. It is possible that PLWH with higher inflammation, and consequently higher levels of either biomarker, could have worse health-related quality of life ${ }^{(29)}$, precluding them from achieving food security. This in turn could put them at higher risk for the adverse outcomes predicted by the two biomarkers. We could therefore extend this hypothesis to postulate that food insecurity could potentially be an intermediary in the pathway between these biomarkers and the adverse outcomes they are associated with. Examination of the directionality of this hypothesis will, however, require better objectification.

Our study describes the epidemiology of food insecurity among PLWH in western India and adds to the sparse literature that exists on the issue from the subcontinent, by using the thoroughly validated HFIAS. It also describes potential associations between hs-CRP, D-dimer and food insecurity which have not been reported before among PLWH, making a case for the greater elucidation of the role of these biochemical markers in food insecurity.

Not unlike other cross-sectional studies, our study is limited too in its failure to establish causality. Thus, while we describe a unidirectional association between food insecurity, hs-CRP and D-dimer, we are unable to comment on the temporal ordering of the relationship between the three. Our sampling methodology also makes it difficult to generalize our findings to other PLWH in India. However, given the constraints of resources in a publicly funded ART centre and the paucity of data on the subject in India, our findings allow us to generate a hypothetical framework to be tested by future longitudinal studies. Our small sample size, which is further reduced when stratified into various levels, results in wide confidence intervals for some of the point estimates. Despite the imprecision for some of these, our findings are consistent with results from other studies, especially those related to sociodemographic variables, and we therefore believe them to be accurate ${ }^{(5,17,23-25)}$. Lastly, we were also unable to comment on whether the prevalence of food insecurity is higher or lower than in the general population in Maharashtra as a comprehensive nutritional survey for the state is available only for children less than 24 months of age ${ }^{(30)}$. 
More than a third of our study population was found to be food insecure, with low family income, primary nonvegetarianism, high hs-CRP and D-dimer proving to be independent risk factors. While the Government of India has recently taken considerable strides to improve treatment outcomes among PLWH by adopting the Test and Treat strategy in $2017^{(1)}$ and consolidating NACO with the tuberculosis programme in $2018^{(31)}$, there is a lack of governmental commitment to improve food security in this vulnerable population. Future studies should seek to understand the role that food insecurity has in determining poor treatment outcomes among Indian PLWH, to provide better locoregional evidence, while incorporating measurements for hs-CRP and D-dimer to objectively understand their role and temporality, relative to food insecurity.

\section{Acknowledgements}

Acknowledgements: This work was made possible through the participation of PLWH; trained counsellors, Manjushree Bendre and Suhasini Surwase; and staff members at the ART centre of Sassoon General Hospitals, Pune, India. Financial support: This study was supported through a grant from TREAT Asia, a programme of amfAR, The Foundation for AIDS Research, with support from the US National Institutes of Health (NIH)'s National Institute of Allergy and Infectious Diseases, the Eunice Kennedy Shriver National Institute of Child Health and Human Development, the National Cancer Institute, the National Institute of Mental Health, and the National Institute on Drug Abuse, as part of the International Epidemiology Databases to Evaluate AIDS (IeDEA; grant number U01AI069907) as well as the NIH-funded Johns Hopkins Baltimore-Washington-India Clinical Trials Unit for NIAID Networks (BWI-CTU; grant number UM1AI069465). Additional support was provided by the Fogarty International Center, NIH (Principal Investigator: R.B., grant number D43TW009574). The content of this paper is solely the responsibility of the authors and does not necessarily represent the official views of the funders. The funders had no role in the design, analysis or writing of this paper. Conflict of interest: None. Authorship: D.K. and N.M. made equal contributions as joint second authors. S.P., I.M., R.B., A.D., N.N., P.M., R.K., M.P., A.G. and V.M. formulated the research question. S.P., D.K., S.S., V.K., D.S., P.D., N.S., N.G., A.D., A.G. and V.M. contributed towards formulation of the study design. S.P., I.M., V.K., D.S., P.D., G.D., N.S., N.G., A.D. and N.N. carried out study proceedings. N.M., I.M., N.G. and V.M. were involved in data analysis for this manuscript. S.P., D.K., N.M., S.S., I.M., M.P. and V.M. contributed to drafting the manuscript. All authors have reviewed this manuscript and approved it. Ethics of human subject participation: This study was conducted according to the guidelines laid down in the Declaration of Helsinki and all procedures involving human subjects/patients were approved by the BJ Government Medical College and Johns Hopkins University Ethics Committees. Written informed consent was obtained from all subjects/patients.

\section{Supplementary material}

To view supplementary material for this article, please visit https://doi.org/10.1017/S136898001900020X

\section{References}

1. National AIDS Control Organisation (2017) National Strategic Plan for HIV/AIDS and STI 2017-2024: Paving the Way for an AIDS Free India. New Delhi: National AIDS Control Organisation, Ministry of Health \& Family Welfare, Government of India; available at http://naco.gov.in/sites/ default/files/Paving\%20the\%20Way\%20for\%20an\%20AIDS $\% 2015122017$.pdf

2. Joint United Nations Programme on HIV and AIDS, World Food Programme \& World Health Organization (2008) UNAIDS Policy Brief: HIV, Food Insecurity and Nutrition. Geneva: UNAIDS; available at http://www.unaids.org/sites/ default/files/media_asset/jc1565_policy_brief_nutrition_long_ en_0.pdf

3. The World Bank (2007) HIV/AIDS, Nutrition, and Food Security: What We Can Do: A Synthesis of International Guidance. Washington, DC: The World Bank; available at http://siteresources.worldbank.org/NUTRITION/Resources/ 281846-1100008431337/HIVAIDSNutritionFoodSecuritylowres. pdf

4. Macallan DC, Noble C, Baldwin C et al. (1995) Energy expenditure and wasting in human immunodeficiency virus infection. $N$ Engl J Med 333, 83-88.

5. Heylen E, Panicker ST, Chandy S et al. (2015) Food insecurity and its relation to psychological well-being among South Indian people living with HIV. AIDS Behav 19, 1548-1558.

6. Masuku MB \& Sithole MM (2009) The impact of HIV/AIDS on food security and household vulnerability in Swaziland. Agrekon 48, 200-222.

7. Weiser SD, Leiter K, Bangsberg DR et al. (2007) Food insufficiency is associated with high-risk sexual behavior among women in Botswana and Swaziland. PLoS Med 4, 1589-1597.

8. Aibibula W, Cox J, Hamelin AM et al. (2016) Food insecurity and low CD4 count among HIV-infected people: a systematic review and meta-analysis. AIDS Care $\mathbf{2 8}$, 1577-1585.

9. Aibibula W, Cox J, Hamelin AM et al. (2017) Association between food insecurity and HIV viral suppression: a systematic review and meta-analysis. AIDS Behav 21, $754-765$.

10. World Health Organization (2008) Regional Consultation on Nutrition and HIV/AIDS: Evidence, Lessons and Recommendations for Action in South-East Asia (Bangkok, Thailand, 8-11 October 2007). SEA-NUT-172. New Delhi: WHO Regional Office for South-East Asia; available at http://apps.who.int/iris/bitstream/handle/10665/205743/ B2153.pdf?sequence $=1$ \&isAllowed $=\mathrm{y}$

11. Department of AIDS Control, National AIDS Control Organisation (2013) Antiretroviral Therapy Guidelines for HIVInfected Adults and Adolescents. New Delhi: National AIDS Control Organisation, Ministry of Health \& Family Welfare, 
Government of India; http://naco.gov.in/sites/default/ files/Antiretroviral\%20Therapy\%20Guidelines $\% 20$ for $\% 20 \mathrm{HIV}$ Infected\%20Adults\%20and\%20Adolescents\%20May\%202013\% 281\%29_0.pdf

12. Mohan S (2017) National Food Security Act, 2013. In Indian Policy and Development: A Manual of National Schemes and International Policy, pp. 153-233. Chennai: McGraw Hill Education (India) Private Limited.

13. Kishore A, Joshi PK \& Hoddinott J (2014) A novel approach to food security. In 2013 Global Food Policy Report, pp. 29-41. Washington, DC: International Food Policy Research Institute.

14. Food and Agriculture Organization of the United Nations, International Fund for Agricultural Development, UNICEF et al. (2017) The State of Food Security and Nutrition in the World 2017: Building Resilience for Peace and Food Security. Rome, FAO; available at http://www.fao.org/3/aI7695e.pdf

15. Food and Agriculture Organization of the United Nations (2016) Asia and the Pacific Regional Overview of Food Insecurity 2016: Investing in a Zero Hunger Generation. Bangkok: FAO Regional Office for Asia and the Pacific; available at http://www.fao.org/3/a-i6481e.pdf

16. Weiser SD, Palar K, Frongillo EA et al. (2014) Longitudinal assessment of associations between food insecurity, antiretroviral adherence and HIV treatment outcomes in rural Uganda. AIDS 28, 115-120.

17. Dasgupta P, Bhattacherjee S \& Das DK (2016) Food security in households of people living with human immunodeficiency virus/acquired immunodeficiency syndrome: a cross-sectional study in a subdivision of Darjeeling District, West Bengal. J Prev Med Public Health 49, 240-248.

18. National AIDS Control Organisation (2014) District HIV/ AIDS Epidemiological Profiles developed through Data Triangulation. Fact Sheets: Maharashtra, pp. 56-57. New Delhi: National AIDS Control Organisation, Ministry of Health \& Family Welfare, Government of India; available at http://naco.gov.in/sites/default/files/Maharashta_DEP.pdf

19. National AIDS Control Organisation \& National Institute of Medical Statistics (2015) India HIV Estimations 2015: Technical Report, p. 2. New Delhi: National AIDS Control Organisation and National Institute of Medical Statistics, Indian Council of Medical Research, Ministry of Health \& Family Welfare, Government of India; available at http:// naco.gov.in/sites/default/files/India\%20HIV\%20Estimations $\% 202015$.pdf
20. Coates J, Swindale A \& Bilinsky P (2007) Household Food Insecurity Access Scale (HFIAS) for Measurement of Food Access: Indicator Guide (v. 3). Washington DC: Food and Nutrition Technical Assistance Project, Academy for Educational Development.

21. Sethi V, Maitra C, Avula R et al. (2017) Internal validity and reliability of experience-based household food insecurity scales in Indian settings. Agric Food Secur 6, 21

22. van Elsland SL, van der Hoeven M, Joshi S et al. (2012) Pressure cooker ownership and food security in Aurangabad, India. Public Health Nutr 15, 818-826.

23. Normen L, Chan K, Braitstein P et al. (2005) Food insecurity and hunger are prevalent among HIV-positive individuals in British Columbia, Canada. J Nutr 135, 820-825.

24. Tsai AC, Bangsberg DR, Emenyonu N et al. (2011) The social context of food insecurity among persons living with HIV/AIDS in rural Uganda. Soc Sci Med 73, 1717-1724.

25. Bukusuba J, Kikafunda JK \& Whitehead RG (2007) Food security status in households of people living with HIV/ AIDS (PLWHA) in a Ugandan urban setting. Br J Nutr 98, 211-217.

26. Triant VA, Meigs JB \& Grinspoon SK (2009) Association of C-reactive protein and HIV infection with acute myocardial infarction. J Acquir Immune Defic Syndr 51, 268-273.

27. Gilotra TS \& Geraci SA (2017) C-reactive protein as an independent cardiovascular risk predictor in HIV + patients: a focused review of published studies. J Clin Med Res $\mathbf{9}$, 891-899.

28. Grund B, Baker JV, Deeks SG et al. (2016) Relevance of interleukin- 6 and d-dimer for serious non-AIDS morbidity and death among HIV-positive adults on suppressive antiretroviral therapy. PloS One 11, e0155100.

29. Althoff KN, Smit M, Reiss P et al. (2016) HIV and ageing: improving quantity and quality of life. Curr Opin HIV AIDS 11, 527-536.

30. Chandrasekhar S, Aguayo VM, Krishna V et al. (2017) Household food insecurity and children's dietary diversity and nutrition in India. Evidence from the comprehensive nutrition survey in Maharashtra. Matern Child Nutr 13, Suppl. 2, e12447.

31. Narayanan N (2018) Health ministry brings TB programme under the supervision of HIV control official. https://scroll.in/pulse/874636/health-ministry-brings-tbprogramme-under-the-supervision-of-hiv-control-official (accessed August 2018). 